\title{
Eating Disorders and Non-suicidal Self-injury: Cluster Analysis Considering Eating Pathology, Emotion Dysregulation, and Negative Urgency
}

Sónia Ferreira Gonçalves ( $\nabla$ sgoncalves@psi.uminho.pt )

University of Minho https://orcid.org/0000-0003-1047-1503

Sofia Ramalho

University of Minho School of Psychology: Universidade do Minho Escola de Psicologia

Bárbara Machado

Portuguese Catholic University: Universidade Catolica Portuguesa

Ana Isabel Vieira

University of Minho School of Psychology: Universidade do Minho Escola de Psicologia

\section{Research Article}

Keywords: Eating disorders, Self-injurious behavior, Emotion regulation, Negative urgency, Cluster Analysis

Posted Date: February 15th, 2021

DOI: https://doi.org/10.21203/rs.3.rs-187711/v1

License: (c) This work is licensed under a Creative Commons Attribution 4.0 International License. Read Full License 


\section{Abstract}

Purpose:

Research on the interplay between eating pathology, difficulties in emotion regulation and negative urgency is needed to better inform and tailor the current intervention approaches for patients with eating disorders and non-suicidal self-injury. The current study aimed to investigate the phenotypic characterization of patients with eating disorders and history of lifetime non-suicidal self-injury when considering eating pathology, emotion dysregulation and negative urgency.

\section{Methods:}

This is a cross-sectional study evaluating 73 patients with eating disorders and history of lifetime non-suicidal self-injury (14-55 years; 68 Female). A cluster analysis (K-means) was performed using eating pathology, difficulties in emotion regulation and negative urgency. Differences between clusters were explored on sociodemographic/psychological variables, distribution of the DSM-5 eating disorder diagnostics and past/current non-suicidal self-injury engagement

\section{Results:}

Three clusters were identified. Cluster $1(n=29)$ (moderate severity) was characterized by high levels of eating pathology, but moderate emotion dysregulation and negative urgency. Cluster $2(n=29)$ (high severity) was characterized by the highest scores in eating pathology, emotion dysregulation and negative urgency. Within this cluster there was the highest prevalence of patients with current non-suicidal self-injury. Cluster $3(n=15)$ (low severity) was characterized by the lowest levels of eating pathology, emotion dysregulation and negative urgency and included more patients with past nonsuicidal self-injury.

\section{Conclusion:}

The three distinctive profiles highlights the importance of emotion dysregulation and negative urgency as a personalized treatment target for eating disorders patients with current NSSI.

Level III: Evidence obtained from well-designed cohort or case-control analytic studies

\section{Introduction}

\section{Definition and prevalence of non-suicidal self-injury in the context of eating disorders}

Non-suicidal self-injury (NSSI) is a deliberate self-inflicted damage to the the body without suicidal intent (Klonsky et al., 2011) and it is associated with different forms of mental illness including eating disorders (ED). According to a metaanalysis published by Cucchi et al. (2016), the average percentage of patients with a lifetime history of NSSI was $27.3 \%$ for ED, namely $21.8 \%$ for anorexia nervosa (AN) and 32.7\% for bulimia nervosa (BN). On the other hand, among those with NSSI, 19.4\% also reported ED symptoms (Muehlenkamp et al., 2012). NSSI is more frequent in bingeeating/purging-type ED than restricting-type ED (Davico et al., 2019). Claes and Muehlenkamp (2014) argued that eating disordered behaviors exist on the continuum of harmful acts with NSSI, with a higher frequency of NSSI, a greater variety of NSSI methods, and a medical treatment of NSSI being related to greater ED severity.

According to Claes et al. (2015) the frequent co-occurrence between ED and NSSI is based on common conditions that include the onset in adolescence or early adulthood and a female preponderance, difficulties in emotion regulation (Lavender et al., 2015) and impulsivity (Claes et al., 2015). 


\section{Emotion regulation, NSSI and ED}

Emotion regulation is a psychological process or capacity involving awareness or understanding of one's emotions, acceptance of emotions experienced, behavioral control during negative emotional states, and flexible use of emotion modulation strategies (Gratz \& Roemer, 2004). A recent meta-analytic review regarding emotion dysregulation and NSSI showed that higher levels of emotion dysregulation were associated with an increased risk of NSSI (You et al., 2018). Results also support that greater emotion dysregulation is associated with higher risk for NSSI among individuals across different contexts, regardless of age or sex (Wolff et al., 2019).

Also, ED are linked to emotion dysregulation. Individuals with ED have been found to show higher levels of emotion dysregulation compared to healthy controls, specifically lower levels of emotional awareness, clarity, and recognition (e.g., Lavender et al., 2015; Monell et al., 2018). In fact, in some extent, both ED and NSSI provide negative reinforcement in the form of escape from, or distraction from, aversive emotional states (Klonsky et al., 2011).

Moreover, both eating disordered behaviors and NSSI may act to serve a similar function. Previous research support the idea that eating disordered behaviors and NSSI may act as an inadequate form to regulate emotions. In fact, a predominant function of NSSI seems to be negative reinforcement. NSSI serves to provide relief or escape from emotional distress and help to regulate emotions (Nock \& Prinstein, 2004). In the same line, the Experiential Avoidance Model of NSSI is based on the idea that NSSI is a negatively reinforced strategy for reducing or ending uncomfortable emotional arousal (Chapman et al., 2006).

Although less studied than NSSI, evidence indicates that some eating disorders symptoms serves also emotion regulation functions by providing a sense of control over body and emotions states (Lavender et al., 2015). More recently, Pisetsky et al. (2017) found that restricting, bingeing and purging are all influenced by emotion dysregulation.

In sum, there is some evidence of functional equivalence between ED and NSSI. Findings revealed that similar intrapersonal such as affect regulation, and interpersonal functions such as interpersonal boundaries and autonomy, may be involved in the development and maintenance of both NSSI and ED behaviors (Muehlenkamp et al., 2019) and previous models of NSSI and ED behaviors highlight the role of similar emotion regulation deficits (e.g., Muehlenkamp et al., 2012).

\section{Negative urgency, NSSI and ED}

Negative urgency refers to the tendency to act impulsively while experiencing extreme aversive emotions. Individuals with high levels of negative urgency intent to reduce negative affect with specific behaviors such as binge eating or cutting, increasing the likelihood of inadequate behaviors through negative reinforcement pathways (Peterson \& Fisher, 2012). As previous noted, research indicates that the co-occurrence of NSSI and ED behaviors is associated with more severe general psychopathology and related mechanisms such as impulsivity and, more specifically, negative urgency. NSSI has, therefore, been conceptualized as the result of difficulties in impulse control, particularly in response to distress (Favazza, 1998; Muehlenkamp et al., 2009).

\section{The present study}

We hypothesized that patients with current NSSI would predominantly fit into a cluster characterized by higher difficulties in emotion regulation, more severe ED psychopathology and more negative urgency. Additionally, patients with $\mathrm{BN}$ and AN binge eating/purging type would predominantly fit in this cluster. 


\section{Method \\ Participants}

From an initial sample 171 outpatients with ED, the final participants of the current study were 73 outpatients with ED who reported a history of engagement in NSSI. The age of participants ranged between 14 and 55 years old $(M=26.42$, $S D=9.35)$ and the mean BMI was $20.30 \mathrm{~kg} / \mathrm{m}^{2}(S D=5.45)$. Most participants were women $(n=68,93.2 \%)$, single $(n=$ $53,73.6 \%)$, students $(n=35,49.3 \%)$, had secondary education $(n=47,65.3 \%)$ and related current psychiatric medication use (e.g., benzodiazepines and antidepressants; $n=61,83.6 \%$ ). The distribution of the sample according to diagnostic group was 25 (32.2\%) with AN restricting type, 7 (9.6\%) with AN binge eating/purging type, 20 (27.4\%) with BN, 6 (8.2\%) with binge eating disorder (BED), and 15 (20.5\%) with other specified ED (OSFED). Forty-five participants (61.6\%) reported engaging in NSSI within the previous several months or more than a year ago and $28(38.4 \%)$ had injured themselves during the preceding week or month of the study. On average, participants used more than one method of NSSI $(M=2.52$, $S D=1.43)$.

\section{Measures}

\section{Sociodemographic and clinical questionnaire}

This questionnaire aims to collect information on gender, age, marital status, education, occupation, psychiatric medication use, weight, height, duration of treatment (months) and duration of the ED (months).

\section{Eating Disorder-15}

The ED-15 (Tatham et al., 2015; Portuguese version Rodrigues et al., 2019) is a brief questionnaire developed to assess eating attitudes over the preceding week through 10 items, using a Likert-type scale ranging from 0 (not at all) to 6 (all the time). Two attitudinal subscales - weight and shape concerns and eating concerns - and a total attitudinal score are obtained. Higher scores suggest greater levels of eating psychopathology. Five additional behavioral items are assessed: binge-eating episodes, self-induced vomiting episodes, laxative misuse days, eating restraint days and excessive exercise days. In this study, Cronbach's $a$ were as follows: total score, $a=.92$; weight and shape concerns, $a=.90$; and eating concerns, $a=.81$.

\section{Difficulties in Emotion Regulation Scale}

The Difficulties in Emotion Regulation Scale (DERS; Gratz \& Roemer, 2004; Portuguese version Coutinho et al., 2010) is a 36-item questionnaire developed to assess difficulties within the following dimensions of emotion dysregulation: limited access to emotion regulation strategies (Strategies); non-acceptance of emotional responses (Non-acceptance); lack of emotional awareness (Awareness); difficulties controlling impulsive behaviors when experiencing negative emotions (Impulses); difficulties engaging in goal-directed behavior when experiencing negative emotions (Goals); and lack of emotional clarity (Clarity). Participants are asked to indicate how often the items apply to themselves, with responses ranging from 1 (almost never) to 5 (almost always). It is possible to obtain a total score (adding all the 36 items) and a score for each subscale. Higher scores indicate greater difficulties in emotion regulation. In this study, we obtained the following Cronbach's $a$ for the subscales of strategies, $a=.92$, non-acceptance, $a=.92$, awareness, $a=.80$, impulses, $a=$ .91 , goals, $a=.90$, and clarity, $a=.80$. Cronbach's $a$ for the total score was .96 . 


\section{UPPS-P Impulsive Behavior Scale - Negative Urgency Subscale}

The UPPS-P Negative Urgency Subscale (Whiteside et al., 2005; Portuguese version Lopes et al., 2013) is a 12-item subscale that assesses the tendency to engage in impulsive behaviors under negative affect. Items are scored on a 4point Likert-type scale ranging from 1 (agree strongly) to 4 (disagree strongly). Higher scores indicate higher negative urgency. Cronbach's $a$ in this study was .87.

\section{Self-Injury Questionnaire - Treatment Related}

The Self-Injury Questionnaire - Treatment Related (SIQ-TR; Claes \& Vandereycken, 2007; Portuguese version Gonçalves, 2008) is a self-report measure that assesses the presence of five methods of NSSI: scratching, bruising, cutting, burning, and biting (or other). For each method, it is asked how long ago the participant had engaged in this form of NSSI: a week; a month; several months; more than a year; and never.

\section{Procedure}

This study was authorized and approved by the University of Minho Ethics Commission-Subcommittee of Ethics for Social and Human Sciences and the Ethics Committee São João Hospital Centre/Faculty of Medicine, University of Porto. Data collection took place in a public psychiatric service that provides specialized treatment for ED in the north of Portugal. Participants were all outpatients and referred for the data collection by clinicians. Information about the research aims and data confidentiality was assured. Participants provided written informed consent before participating.

\section{Statistical analyses}

The statistical analyses were conducted with IBM SPSS Statistics 27.0 (SPSS, Inc., Chicago, IL). Descriptive statistics examined demographic and clinical characteristics of the sample, including ED diagnoses and NSSI. A cluster analysis was performed with the total scores of ED-15, DERS and UPPS-P negative urgency to identify different groups based on eating psychopathology, emotion dysregulation and negative urgency. First, a hierarchical cluster analysis, using the between-groups linkage and the squared Euclidean distance, was performed to estimate the probable number of clusters. Second, a non-hierarchical procedure, the K-means cluster analysis, was performed to find the optimal cluster solution. In this analysis, the number of clusters determined by the hierarchical procedure was pre-specified. The Silhouettes coefficient was also used to measure the goodness of the final cluster solution. This coefficient allows to verify if the elements within a cluster are similar or cohesive to each other, while the clusters themselves are different or separated. The Silhouette values range from -1 to +1 . In a good solution, the coefficient close to the value of 1 .

One-way analyses of variance (ANOVA) were used to determine differences among the clusters regarding total scores of ED-15, DERS and UPPS-P negative urgency, as well as regarding age, BMI, durations of the ED or treatment, and number of methods of NSSI. One-way multivariate analyses of variance (MANOVA) were used to analyze differences among the clusters in eating attitudes and dimensions of emotion dysregulation. Kruskal-Wallis tests $\left(\chi^{2}\right)$ were also used to analyze differences among the clusters in eating behaviors (ED-15). Finally, Chi-Square tests $\left(\chi^{2}\right)$ were conducted to determine the distribution of current (in the preceding week or month of the study) and past (within the previous several months or more than a year ago) NSSI across clusters. The relevant assumptions of all statistical analyses were tested; $p$ values < .05 were considered significant.

\section{Results}




\section{Cluster analysis}

Based on the total scores of ED-15, DERS and UPPS-P negative urgency, three clusters were estimated by the hierarchical cluster analysis, which coincided with the optimal solution chosen by the K-means cluster analysis. The Silhouettes coefficient was used as a measure of the goodness of the final cluster solution and its mean value was .301 (min. -.086; max. .508), suggesting a fair fitting. Cluster 1 comprised $39.7 \%$ of the sample $(n=29)$, Cluster 2 also included $39.7 \%$ of the sample $(n=29)$ and Cluster 3 represented $20.5 \%$ of the participants $(n=15)$. The standardized scores for the three clusters are presented in Figure 1. Cluster 1 represented the participants with high ED-15 total scores relative to the sample mean, as well as the participants with lower than average total scores of DERS and UPPS-P negative urgency. Cluster 2 was characterized by participants with the highest scores in the three variables relative to the sample means. Cluster 3 represented the participants with the lowest scores in the three variables relative to the sample means.

\section{Comparison among the Clusters}

A series of one-way ANOVAs were conducted to test differences among the clusters in the main variables (Table 1). The results revealed significant differences among the three clusters in the total scores of ED-15, $F(2,70)=22.18, p<.001$, DERS, $F(2,32)=63.22, p<.001$, and UPPS-P negative urgency, $F(2,32)=48.30, p<.001$. In pairwise comparisons, the ED-15 total score in Cluster 1 was significantly higher than in Cluster 3 (mean difference $=2.09, p<.001$ ), and the ED-15 total score in Cluster 2 was also significantly higher than in Cluster 3 (mean difference $=2.59, p<.001$ ). No differences were found between the Clusters 1 and 2 in ED-15 total score (mean difference $=-.50, p=.34$ ). For DERS total score, Cluster 1 scored significantly lower than Cluster 2 (mean difference $=-40.43, p<.001$ ) and scored significantly higher than Cluster 3 (mean difference $=19.91, p=.04$ ). Cluster 2 scored significantly higher than Cluster 3 (mean difference $=$ $60.34, p<.001$ ). For UPPS-P negative urgency, Cluster 1 also scored significantly lower than Cluster 2 (mean difference = $-6.38, p<.001$ ) and scored significantly higher than Cluster 3 (mean difference $=9.07, p=.04$ ). Cluster 2 scored significantly higher than Cluster 3 (mean difference $=15.45, p<.001$ ).

Additionally, the differences among the clusters in attitudes and eating behaviors, as well as in the dimensions of emotion dysregulation were analyzed (Table 1). Regarding eating attitudes, the MANOVA revealed a significant overall effect of the clusters on the subscales of the ED-15, $F(4,138)=9.83, p<.001$; Wilk's $\lambda=.61$, partial $\eta^{2}=.22$. Univariate ANOVAs indicated that both weight and shape concerns, $F(2,70)=21.29, p<.001$, and eating concerns, $F(2,70)=$ $14.41, p<.001$, were significantly different among clusters. Post-hoc comparisons suggested that weight and shape concerns in Cluster 1 were significantly higher than those in Cluster 3 (mean difference $=2.19, p<.001$ ). Weight and shape concerns in Cluster 2 were also significantly higher than those in Cluster 3 (mean difference $=2.73, p<.001$ ). Additionally, eating concerns in Cluster 1 were significantly higher than those in Cluster 3 (mean difference $=1.96, p<$ .001), as well as eating concerns in Cluster 2 were significantly higher than those in Cluster 3 (mean difference $=2.41, p$ $<.001$ ). No differences were found between the Clusters 1 and 2 in weight and shape concerns (mean difference $=-.54, p$ $=.35$ ) or eating concerns (mean difference $=-.46, p=.54$ ).

For eating behaviors, Kruskal-Wallis tests showed significant differences among the clusters in binge-eating episodes, $\chi^{2}$ $(2)=9.28, p=.010$, vomiting episodes, $\chi^{2}(2)=10.40, p=.006$, eating restraint days, $\chi^{2}(2)=8.74, p=.013$, and excessive exercise days, $\chi^{2}(2)=8.47, p=.015$. No significant differences were found among the clusters on laxative misuse days, $\chi^{2}(2)=4.00, p=.135$. Mann-Whitney tests with Bonferroni correction suggested that participants from Cluster 1 scored significantly higher than those from Cluster 3 in binge-eating episodes, $U=144.50, p=.021$, vomiting episodes, $U=$ $120.00, p=.003$, and restraint days, $U=135.50, p=.026$. For excessive exercise days, no differences were found between the Clusters 1 and $3, U=160.00, p=.077$. Participants from Cluster 2 scored significantly higher than those from Cluster 3 in binge-eating episodes, $U=112.00, p=.002$, vomiting episodes, $U=112.50, p=.002$, eating restraint days, $U=108.00$, 
$p=.004$, and excessive exercise days, $U=117.00, p=.005$. No differences were found between the Clusters 1 and 2 in all eating behaviors.

With respect to the dimensions of emotion dysregulation, the MANOVA revealed a significant overall effect of the clusters on the six subscales of the DERS, $F(12,130)=10.65, p<.001$; Wilk's $\lambda=.25$, partial $\eta^{2}=.50$. Except for awareness, $F(2$, $70)=2.03, p=.139$, univariate ANOVAs indicated that strategies, $F(2,70)=55.44, p<.001$, nonacceptance, $F(2,70)=$

28.87, $p<.001$, impulse, $F(2,70)=39.05, p<.001$, goals, $F(2,70)=21.86, p<.001$, and clarity, $F(2,70)=24.10, p<.001$, were significantly different among clusters. Post-hoc comparisons suggested that participants assigned to Cluster 1 scored significantly lower than those assigned to Cluster 2 in strategies (mean difference $=-10.55, p<.001$ ), nonacceptance (mean difference $=-9.24, p<.001)$, impulse (mean difference $=-8.79, p<.001)$, goals $($ mean difference $=$ $-4.31, p<.001$ ) and clarity (mean difference $=-4.55, p<.001$ ). On the other hand, the Cluster 1 scored significantly higher than the Cluster 3 in strategies (mean difference $=6.60, p<.001$ ), goals (mean difference $=4.71, p=.003$ ) and lack of emotional clarity (mean difference $=3.41, p=.016$ ). Finally, the Cluster 2 scored significantly higher than the Cluster 3 in strategies $($ mean difference $=17.15, p<.001)$, nonacceptance $($ mean difference $=10.69, p<.001)$, impulse (mean difference $=12.48, p<.001)$, goals (mean difference $=9.02, p<.001)$ and clarity (mean difference $=9.02, p<.001)$.

No significant differences were found among the clusters regarding age, BMI and durations of the ED or treatment (Table 1). Regarding the distribution of the DSM-5 ED diagnostics into each cluster (Table 2), Cluster 1 included equal proportions of patients with AN restricting type, BN and OSFED. Most patients in Cluster 2 were diagnosed with BN, followed by patients with AN restricting type. Cluster 3 did not include participants with AN binge eating/purging-type and most of the patients in this cluster were diagnosed with AN restricting type.

\section{Characteristics of NSSI in each Cluster}

Chi-square tests were conducted to determine the distribution of current (in the preceding week or month of the study) and past (within the previous several months or more than a year ago) NSSI across clusters. A significant relationship was found between cluster membership and engagement in current or past NSSI, $\chi^{2}(2)=14.37, p=.001$. While in Cluster 2 , most participants $(n=17,58.6 \%)$ reported NSSI during the preceding week or month of the study, in Clusters 1 ( $n=18$, $62.1 \%)$ and $3(n=15,100 \%)$, more participants reported NSSI within the previous several months or more than a year ago.

There were no significant differences among the clusters in number of methods of NSSI, $F(2,70)=.24, p=.79$. As outlined in Table 3, the most common method of NSSI in the three clusters was cutting.

To sum up, Cluster 1, compared to the sample mean, included participants with higher levels of eating pathology. It was also characterized by lower emotion dysregulation and negative urgency than Cluster 2, but both higher than Cluster 3. The most frequent diagnoses in this cluster were AN restricting type, BN and OSFED. Finally, Cluster 1 included more participants with past NSSI. Cluster 1 was labeled in this study as the "moderate severity cluster".

Cluster 2 included the participants with the highest scores in the main variables, namely greater levels of eating pathology, emotion dysregulation, and negative urgency than the other clusters. The most frequent diagnoses in this cluster were BN and AN restricting type. Cluster 2 also included more participants with current NSSI. It was labeled as the "high severity cluster".

Cluster 3 included the participants with the lowest levels of eating pathology, emotion dysregulation and negative urgency. The most frequent diagnosis was AN restricting type, and this cluster included more participants with past NSSI. Cluster 3 was labeled in this study as the "low severity cluster". 


\section{Discussion}

The aim of the present study was to explore empirical severity clusters with outpatients with ED and lifetime NSSI regarding ED symptomatology, emotion dysregulation, and negative urgency. A three-cluster structure has emerged based on the factors considered. These clusters ranged from a less dysfunctional cluster (low severity) to moderate and highly severity clusters of patients.

The first cluster, the "moderate severity" cluster, included participants with high levels of eating pathology but moderate levels of emotion dysregulation and negative urgency. This cluster included more participants with past NSSI. (more than one year) Therefore, we hypothesize that past history of NSSI in patients with ED was equally related to both less difficulties in emotion regulation and lower negative urgency, when compared to patients with current history of NSSI. These moderate difficulties, concerning underlying mechanisms common in ED and NSSI found in this cluster, maybe explained by higher ED symptomatology precisely when NSSI is not a current symptom. In fact, no differences were found between the clusters 1 ("moderate severity" cluster) and 2 ("high severity" cluster) on ED-15 total score and on all eating disordered behaviors evaluated (e.g., binge-eating).

The second cluster, the "high severity" cluster, was characterized by high difficulties in emotion regulation, high ED symptomatology as well by high negative urgency. Within this cluster there was the highest prevalence of patients with current NSSI. Although all the patients in this study reported some kind of NSSI across the lifespan, we found that present NSSI is related with highest severity in ED symptomatology and worst psychopathological state in general, what is in accordance with current literature (Claes \& Muehlenkamp, 2014; Islam et al., 2015). Additionally, within this "high severity" cluster there was the highest prevalence of patients with BN. This is also consistent with previous studies that showed that NSSI can be a part of a spectrum of multi-impulsive behaviors that include binging and purging behaviors and both NSSI and eating disordered behaviors may represent attempts to deal and regulate negative emotions (GómezExpósito et al., 2016; Muehlenkamp et al., 2012; Wolff et al., 2019). In sum, the "high severity cluster" might be driven by the comorbid ED symptomatology with specific high difficulties such as emotion dysregulation and negative urgency that are underlying mechanisms that possibly maintain current NSSI. Thus, when considering treatment for patients who are in this cluster, it is important to target not only eating symptomatology but also factors that may be responsible for the current maintenance of NSSI. Addressing emotion regulation and impulsivity could be an important focus of treatment in this "high severity" cluster.

The third cluster, the "low severity" cluster, was the one with the lowest scores on ED symptomatology, emotion dysregulation and negative urgency. We hypothesized that this cluster integrated the less dysfunctional patients with ED and with better prognosis. This cluster also included more participants with past NSSI and the highest percentage of patients with AN restricting type. These results are in line with previous research (cf., for a review Cucchi et al., 2016) that showed that NSSI is more prevalent among patients with BN and with AN binge eating/purging type compared to patients with AN restrictive type.

In sum, the results of the current study describe a three-cluster structure that range from a less severity and less dysfunctional cluster to a high severity cluster. Our intent was to contribute to a better understanding of NSSI in the context of ED and to a better individualization of treatment by identifying possible mechanisms underlying both conditions and levels of severity.

This study has several limitations. First, the small number of participants and consequently the small dimension of participants in each cluster. Second, the cross-sectional nature of the study; for future studies, it will be important to explore longitudinally how the behaviors and mechanisms evaluated interact during time. Finally, the use of self-report measures to evaluate behaviors such as NSSI and ED symptoms; for future studies, it will be important to use semistructured interviews to better explore and understand both conditions. Despite the limitations, as far as we know, this 
study is the first to investigate different clusters among Portuguese patients with ED who have also engaged in NSSI. Thus, this study provides important information about the distinct features of subgroups with ED and lifetime history of NSSI, and the results suggest that emotion regulation and impulse control should also be assessed and incorporated in the interventions, especially among individuals with a more severe ED and current NSSI.

\section{Strengths and limits:}

This is a cross-sectional study evaluating 73 patients with eating disorders and history of lifetime non-suicidal self-injury, that aimed to investigate the phenotypic characterization of patients with both conditions, using cluster analysis (Kmeans), when considering eating pathology, emotion dysregulation and negative urgency.

\section{What is already known on this subject?}

The existing literature indicates a high co-occurrence of ED behaviors and NSSI, as well as a considerable mechanistic similarity between these behaviors. Previous findings also revealed that similar intrapersonal (e.g., affect regulation, marking distress) and interpersonal functions (e.g., interpersonal boundaries, autonomy) may motivate NSSI and ED behaviors. Previous models of NSSI and ED behaviors highlight the role of similar emotion regulation deficits.

\section{What your study adds?}

This study provides important information about the distinct features of subgroups with ED and lifetime history of NSSI. The results describe a three-cluster structure that range from a less severity cluster to a high severity cluster in dimensions such as eating symptomatology, emotions dysregulation and negative urgency. The results intent to contribute to a better understanding of NSSI in the context of ED and to a better personalized treatment by identifying possible mechanisms underlying both conditions and levels of severity.

\section{References}

1. Chapman, A. L., Gratz, K. L., \& Brown, M. Z. (2006). Solving the puzzle of deliberate self-harm: The experiential avoidance model. Behaviour Research and Therapy, 44(3), 371-394. https://doi.org/10.1016/j.brat.2005.03.005

2. Claes, L., \& Muehlenkamp, J. J. (2014). Non-suicidal self-injury and eating disorders: Dimensions of self-harm. In L. Claes, \& J. J. Muehlenkamp (Eds.), Non-suicidal self-injury in eating disorders: Advancements in etiology and treatment (pp. 3-18). Heidelberg, Germany: Springer. https://doi.org/10.1007/978-3-642-40107-7

3. Claes, L., Islam, M. A., Fagundo, A. B., Jimenez-Murcia, S., Granero, R., Agüera, Z., Rossi, E., Menchón, J. M., \& Fernández-Aranda, F. (2015). The relationship between non-suicidal self-injury and the UPPS-P impulsivity facets in eating disorders and healthy controls. PloS One, 10(5), e0126083. https://doi.org/10.1371/journal.pone.0126083

4. Claes, L., \& Vandereycken, W. (2007). The self-injury questionnaire - treatment related (SIQ-TR): Construction, reliability, and validity in a sample of female eating disorder patients. In P. M. Goldfarb (Ed.), Psychological tests and testing research trends (pp. 111-139). Nova Science Publishers.

5. Coutinho, J., Ribeiro, E., Ferreirinha, R., \& Dias, P. (2010). The Portuguese version of the difficulties in emotion regulation scale and its relationship with psychopathological symptoms. Revista de Psiquiatria Clínica, 37, 145151. https://doi.org/10.1590/S0101-60832010000400001

6. Cucchi, A., Ryan, D., Konstantakopoulos, G., Stroumpa, S., Kaçar, A. Ş., Renshaw, S., Landau, S., \& Kravariti, E. (2016). Lifetime prevalence of non-suicidal self-injury in patients with eating disorders: A systematic review and meta- 
analysis. Psychological Medicine, 46(7), 1345-1358. https://doi.org/10.1017/s0033291716000027

7. Davico, C., Amianto, F., Gaiotti, F., Lasorsa, C., Peloso, A., Bosia, C., Vesco, S., Arletti, L., Reale, L., \& Vitiello, B. (2019). Clinical and personality characteristics of adolescents with anorexia nervosa with or without non-suicidal selfinjurious behavior. Comprehensive Psychiatry, 94, Article 152115.

https://doi.org/10.1016/j.comppsych.2019.152115

8. Favazza, A. R. (1998). The coming of age of self-mutilation. The Journal of nervous and mental disease, 186(5), 259-268. https://doi.org/10.1097/00005053-199805000-00001

9. Gómez-Expósito, A., Wolz, I., Fagundo, A. B., Granero, R., Steward, T., Jiménez-Murcia, S., Agüera, Z., \& FernándezAranda, F. (2016). Correlates of non-suicidal self-injury and suicide attempts in bulimic spectrum disorders. Frontiers in Psychology, 7, Article 1244. https://doi.org/10.3389/fpsyg.2016.01244

10. Gonçalves, S. (2008). Escala de Avaliação de Ferimentos Autoinfligidos [The Self-Injury Questionnaire Treatment Related (SIQ-TR)] [Unpublished manuscript]. Psychology Research Center (CIPsi), School of Psychology, University of Minho.

11. Gratz, K. L., \& Roemer, L. (2004). Multidimensional assessment of emotion regulation and dysregulation: Development, factor structure, and initial validation of the Difficulties in Emotion Regulation Scale. Journal of Psychopathology and Behavioral Assessment, 26(1), 41-54. https://doi.org/10.1007/s10862-008-9102-4

12. Islam, M. A., Steiger, H., Jimenez-Murcia, S., Israel, M., Granero, R., Agüera, Z., Castro, R., Sánchez, I., Riesco, N., Menchón, J. M., \& Fernández-Aranda, F. (2015). Non-suicidal self-injury in different eating disorder types: Relevance of personality traits and gender. European Eating Disorders Review, 23(6), 553-560.

https://doi.org/10.1002/erv.2374

13. Klonsky, E. D., Muehlenkamp, J. J., Lewis, S. P., \& Walsh, B. (2011). Nonsuicidal self-injury. Hogrefe Publishing.

14. Lavender, J. M., Wonderlich, S. A., Engel, S. G., Gordon, K. H., Kaye, W. H., \& Mitchell, J. E. (2015). Dimensions of emotion dysregulation in anorexia nervosa and bulimia nervosa: A conceptual review of the empirical literature. Clinical psychology Review, 40, 111-122. https://doi.org/10.1016/j.cpr.2015.05.010

15. Lopes, P., Oliveira, J., Brito, R., Gamito, P., Rosa, P., \& Trigo, H. (2013). UPPS-P, versão portuguesa [Unpublished manuscript]. Universidade Lusófona de Humanidades e Tecnologias.

16. Monell, E., Clinton, D., \& Birgegård, A. (2018). Emotion dysregulation and eating disorders Associations with diagnostic presentation and key symptoms. International Journal of Eating Disorders, 51(8), 921-930. https://doi.org/10.1002/eat.22925

17. Muehlenkamp, J. J., Engel, S. G., Wadeson, A., Crosby, R. D., Wonderlich, S. A., Simonich, H., \& Mitchell, J. E. (2009). Emotional states preceding and following acts of non-suicidal self-injury in bulimia nervosa patients. Behaviour Research and Therapy, 47(1), 83-87. https://doi.org/10.1016/j.brat.2008.10.011

18. Muehlenkamp, J. J., Peat, C. M., Claes, L., \& Smits, D. (2012). Self-injury and disordered eating: Expressing emotion dysregulation through the body. Suicide and Life-Threatening Behavior, 42(4), 416-425.

https://doi.org/10.1111/j.1943-278X.2012.00100.x

19. Muehlenkamp, J. J., Suzuki, T., Brausch, A. M., \& Peyerl, N. (2019). Behavioral functions underlying NSSI and eating disorder behaviors. Journal of Clinical Psychology, 75(7), 1219-1232. https://doi.org/10.1002/jclp.22745

20. Nock, M. K., \& Prinstein, M. J. (2004). A functional approach to the assessment of self-mutilative behavior. Journal of Consulting and Clinical Psychology, 72(5), 885-890. https://doi.org/10.1037/0022-006X.72.5.885

21. Peterson, C. M., \& Fischer, S. (2012). A prospective study of the influence of the UPPS model of impulsivity on the cooccurrence of bulimic symptoms and non-suicidal self-injury. Eating behaviors, 13(4), 335-341.

https://doi.org/10.1016/j.eatbeh.2012.05.007

Page $10 / 15$ 
22. Pisetsky, E. M., Haynos, A. F., Lavender, J. M., Crow, S. J., \& Peterson, C. B. (2017). Associations between emotion regulation difficulties, eating disorder symptoms, non-suicidal self-injury, and suicide attempts in a heterogeneous eating disorder sample. Comprehensive psychiatry, 73, 143-150. https://doi.org/10.1016/j.comppsych.2016.11.012

23. Rodrigues, T., Vaz, A. R., Silva, C., Conceição, E., \& Machado, P. P. P. (2019). Eating Disorder-15 (ED-15): Factor structure, psychometric properties, and clinical validation. European Eating Disorders Review, 27, 1-10. https://doi.org/10.1002/erv.2694

24. Tatham, M., Turner, H., Mountford, V. A., Tritt, A., Dyas, R., \& Waller, G. (2015). Development, psychometric properties and preliminary clinical validation of a brief, session-by-session measure of eating disorder cognitions and behaviors: The ED-15. International Journal of Eating Disorders, 48(7), 1005-1015.

https://doi.org/10.1002/eat.22430

25. Whiteside, S. P., Lynam, D. R., Miller, J. D., \& Reynolds, S. K. (2005). Validation of the UPPS impulsive behavior scale: A four-factor model of impulsivity. European Journal of Personality, 19(7), 559-574. https://doi.org/10.1002/per.556

26. Wolff, J. C., Thompson, E., Thomas, S. A., Nesi, J., Bettis, A. H., Ransford, B., ... \& Liu, R. T. (2019). Emotion dysregulation and non-suicidal self-injury: A systematic review and meta-analysis. European Psychiatry, 59, 25-36.

27. You, J., Ren, Y., Zhang, X., Wu, Z., Xu, S., \& Lin, M. P. (2018). Emotional dysregulation and nonsuicidal self-injury: A meta-analytic review. Neuropsychiatry, 8(2), 733-748. https://doi.org/10.4172/Neuropsychiatry.1000399

\section{Tables}

Table 1

Differences among the clusters in the main variables 


\begin{tabular}{|c|c|c|c|c|c|c|c|c|c|c|}
\hline & \multicolumn{2}{|c|}{$\begin{array}{l}\text { Cluster } 1 \\
(n=29)\end{array}$} & \multicolumn{2}{|c|}{$\begin{array}{l}\text { Cluster } 2 \\
(n=29\end{array}$} & \multicolumn{2}{|c|}{$\begin{array}{l}\text { Cluster } 3 \\
(n=15)\end{array}$} & \multirow[t]{2}{*}{$\begin{array}{l}\text { Test } \\
\text { value }\end{array}$} & \multicolumn{3}{|c|}{ Post hoc tests } \\
\hline & $M$ & SD & $M$ & SD & $M$ & SD & & $\begin{array}{l}\text { Cluster } \\
1 \text { vs } \\
\text { Cluster } \\
2\end{array}$ & $\begin{array}{l}\text { Cluster } \\
1 \text { vs } \\
\text { Cluster } \\
3\end{array}$ & $\begin{array}{l}\text { Cluster } \\
2 \text { vs } \\
\text { Cluster } \\
3\end{array}$ \\
\hline $\begin{array}{l}\text { ED-15 total } \\
\text { score }\end{array}$ & 3.84 & 1.19 & 4.35 & 1.32 & 1.75 & 1.21 & $22.18^{\star \star \star a}$ & ns & $\begin{array}{l}\text { Cluster } \\
1> \\
\text { Cluster } \\
3\end{array}$ & $\begin{array}{l}\text { Cluster } \\
2> \\
\text { Cluster } \\
3\end{array}$ \\
\hline $\begin{array}{l}\text { DERS total } \\
\text { score }\end{array}$ & 103.71 & 18.46 & 144.14 & 14.11 & 83.80 & 26.18 & $63.22^{\star \star \star b}$ & $\begin{array}{l}\text { Cluster } \\
1< \\
\text { Cluster } \\
2\end{array}$ & $\begin{array}{l}\text { Cluster } \\
1> \\
\text { Cluster } \\
3\end{array}$ & $\begin{array}{l}\text { Cluster } \\
2> \\
\text { Cluster } \\
3\end{array}$ \\
\hline $\begin{array}{l}\text { UPPS-P } \\
\text { negative } \\
\text { urgency }\end{array}$ & 33.20 & 2.980 & 24.13 & 6.13 & 33.88 & 7.04 & $48.30^{\star \star \star b}$ & $\begin{array}{l}\text { Cluster } \\
1< \\
\text { Cluster } \\
2\end{array}$ & $\begin{array}{l}\text { Cluster } \\
1> \\
\text { Cluster } \\
3\end{array}$ & $\begin{array}{l}\text { Cluster } \\
2> \\
\text { Cluster } \\
3\end{array}$ \\
\hline $\begin{array}{l}\text { ED-15 Weight } \\
\text { and shape } \\
\text { concerns }\end{array}$ & 3.94 & 1.37 & 4.47 & 1.30 & 1.74 & 1.37 & $21.29^{\star \star \star} \mathrm{C}$ & ns & $\begin{array}{l}\text { Cluster } \\
1> \\
\text { Cluster } \\
3\end{array}$ & $\begin{array}{l}\text { Cluster } \\
2> \\
\text { Cluster } \\
3\end{array}$ \\
\hline $\begin{array}{l}\text { ED-15 Eating } \\
\text { concerns }\end{array}$ & 3.71 & 1.24 & 4.16 & 1.72 & 1.75 & 1.20 & $14.41^{\star \star \star_{C}}$ & ns & $\begin{array}{l}\text { Cluster } \\
1> \\
\text { Cluster } \\
3\end{array}$ & $\begin{array}{l}\text { Cluster } \\
2> \\
\text { Cluster } \\
3\end{array}$ \\
\hline $\begin{array}{l}\text { ED-15 Binge- } \\
\text { eating } \\
\text { episodes }\end{array}$ & 2.35 & 4.69 & 3.38 & 5.12 & .07 & .26 & $9.28^{\star \star d}$ & ns & $\begin{array}{l}\text { Cluster } \\
1> \\
\text { Cluster } \\
3\end{array}$ & $\begin{array}{l}\text { Cluster } \\
2> \\
\text { Cluster } \\
3\end{array}$ \\
\hline $\begin{array}{l}\text { ED-15 Vomiting } \\
\text { episodes }\end{array}$ & 3.24 & 5.91 & 1.66 & 3.17 & .00 & .00 & $10.40^{\star \star d}$ & ns & $\begin{array}{l}\text { Cluster } \\
1> \\
\text { Cluster } \\
3\end{array}$ & $\begin{array}{l}\text { Cluster } \\
2> \\
\text { Cluster } \\
3\end{array}$ \\
\hline $\begin{array}{l}\text { ED-15 Laxative } \\
\text { misuse days }\end{array}$ & .86 & 1.77 & .79 & 2.02 & .00 & .00 & $4.00^{d}$ & - & - & - \\
\hline $\begin{array}{l}\text { ED-15 Eating } \\
\text { restraint days }\end{array}$ & 2.45 & 2.69 & 3.34 & 3.13 & .93 & 2.28 & $8.74^{\star d}$ & ns & $\begin{array}{l}\text { Cluster } \\
1> \\
\text { Cluster } \\
3\end{array}$ & $\begin{array}{l}\text { Cluster } \\
2> \\
\text { Cluster } \\
3\end{array}$ \\
\hline $\begin{array}{l}\text { ED-15 Exercise } \\
\text { days }\end{array}$ & 1.59 & 2.49 & 2.76 & 3.10 & .40 & 1.30 & $8.47^{\star d}$ & ns & ns & $\begin{array}{l}\text { Cluster } \\
2> \\
\text { Cluster } \\
3\end{array}$ \\
\hline
\end{tabular}

Note. DERS = Difficulties in Emotion Regulation Scale; ED-15 = Eating Disorder-15. ${ }^{a}$ ANOVA (post hoc Gabriel); ${ }^{b}$ ANOVA (Welch's F and post hoc Games-Howell); 'MANOVA with pairwise univariate contrasts (post hoc Gabriel); ${ }^{\mathrm{d}}$ Kruskal-Wallis test (Mann-Whitney tests with Bonferroni correction).

${ }^{*} \mathrm{p}<.05 ;{ }^{* *} \mathrm{p}<0.01 ;{ }^{* * *} \mathrm{p}<.001$ 


\begin{tabular}{|c|c|c|c|c|c|c|c|c|c|c|}
\hline & \multicolumn{2}{|c|}{$\begin{array}{l}\text { Cluster } 1 \\
(n=29)\end{array}$} & \multicolumn{2}{|c|}{$\begin{array}{l}\text { Cluster } 2 \\
(n=29\end{array}$} & \multicolumn{2}{|c|}{$\begin{array}{l}\text { Cluster } 3 \\
(n=15)\end{array}$} & \multirow[t]{2}{*}{$\begin{array}{l}\text { Test } \\
\text { value }\end{array}$} & \multicolumn{3}{|c|}{ Post hoc tests } \\
\hline & M & SD & $M$ & SD & $M$ & SD & & $\begin{array}{l}\text { Cluster } \\
1 \text { vs } \\
\text { Cluster } \\
2\end{array}$ & $\begin{array}{l}\text { Cluster } \\
1 \text { vs } \\
\text { Cluster } \\
3\end{array}$ & $\begin{array}{l}\text { Cluster } \\
2 \text { vs } \\
\text { Cluster } \\
3\end{array}$ \\
\hline $\begin{array}{l}\text { DERS } \\
\text { Strategies }\end{array}$ & 23.86 & 6.16 & $3 ., 41$ & 4.01 & 17.27 & 6.38 & $55.44^{\star \star \star} \mathrm{C}$ & $\begin{array}{l}\text { Cluster } \\
1< \\
\text { Cluster } \\
2\end{array}$ & $\begin{array}{l}\text { Cluster } \\
1> \\
\text { Cluster } \\
3\end{array}$ & $\begin{array}{l}\text { Cluster } \\
2> \\
\text { Cluster } \\
3\end{array}$ \\
\hline $\begin{array}{l}\text { DERS } \\
\text { Nonacceptance }\end{array}$ & 16.45 & 5.44 & 25.69 & 4.41 & 15.00 & 6.87 & $28.87^{\star \star \star} \mathrm{C}$ & $\begin{array}{l}\text { Cluster } \\
1< \\
\text { Cluster } \\
2\end{array}$ & ns & $\begin{array}{l}\text { Cluster } \\
2> \\
\text { Cluster } \\
3\end{array}$ \\
\hline $\begin{array}{l}\text { DERS } \\
\text { Awareness }\end{array}$ & 17.90 & 5.14 & 20.10 & 5.35 & 17.07 & 5.60 & $2.03^{c}$ & - & - & - \\
\hline DERS Impulse & 15.69 & 5.238 & 24.48 & 4.06 & 12.00 & 5.82 & $39.05^{\star \star \star} \mathrm{c}$ & $\begin{array}{l}\text { Cluster } \\
1< \\
\text { Cluster } \\
2\end{array}$ & ns & $\begin{array}{l}\text { Cluster } \\
2> \\
\text { Cluster } \\
3\end{array}$ \\
\hline DERS Goals & 17.31 & 4.61 & 21.62 & 3.74 & 12.60 & 4.97 & $21.86^{\star \star \star c}$ & $\begin{array}{l}\text { Cluster } \\
1< \\
\text { Cluster } \\
2\end{array}$ & $\begin{array}{l}\text { Cluster } \\
1> \\
\text { Cluster } \\
3\end{array}$ & $\begin{array}{l}\text { Cluster } \\
2> \\
\text { Cluster } \\
3\end{array}$ \\
\hline DERS Clarity & 13.28 & 4.17 & 17.83 & 3.19 & 9.87 & 4.02 & $24.10^{\star \star \star} \mathrm{C}$ & $\begin{array}{l}\text { Cluster } \\
1< \\
\text { Cluster } \\
2\end{array}$ & $\begin{array}{l}\text { Cluster } \\
1> \\
\text { Cluster } \\
3\end{array}$ & $\begin{array}{l}\text { Cluster } \\
2> \\
\text { Cluster } \\
3\end{array}$ \\
\hline Age & 24.21 & 7.52 & 28.21 & 11.40 & 27.27 & 7.67 & $1.42^{\mathrm{a}}$ & - & - & - \\
\hline BMI & 21.06 & 5.73 & 20.16 & 5.34 & 19.11 & 5.22 & $.65^{a}$ & - & - & - \\
\hline $\begin{array}{l}\text { Duration of } \\
\text { treatment }\end{array}$ & 29.97 & 46.20 & 27.17 & 46.79 & 31.33 & 40.60 & $.05^{\mathrm{a}}$ & - & - & - \\
\hline $\begin{array}{l}\text { Duration of the } \\
\text { ED }\end{array}$ & 71.69 & 65.29 & 83.14 & 81.43 & 104.13 & 72.67 & $.96^{\mathrm{a}}$ & - & - & - \\
\hline \multicolumn{11}{|c|}{ 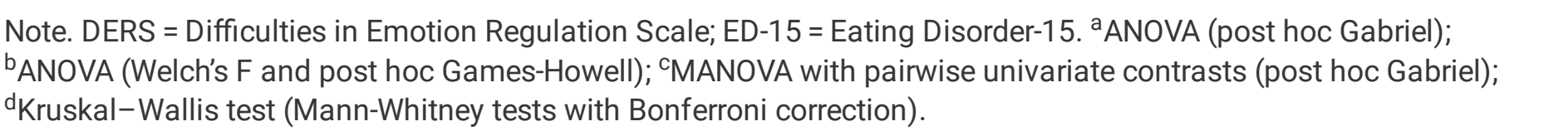 } \\
\hline 5. & & & & & & & & & & \\
\hline
\end{tabular}

Table 2

Distribution of the DSM-5 ED diagnostics into each cluster 


\begin{tabular}{|c|c|c|c|c|c|c|}
\hline & \multicolumn{2}{|c|}{ Cluster 1} & \multicolumn{2}{|c|}{ Cluster 2} & \multicolumn{2}{|c|}{ Cluster 3} \\
\hline & $\mathbf{n}$ & $\%$ & $\mathbf{n}$ & $\%$ & $\mathrm{n}$ & $\%$ \\
\hline \multicolumn{7}{|l|}{ Diagnosis } \\
\hline OSFED & 8 & 27.6 & 2 & 6.9 & 5 & 33.3 \\
\hline AN restricting type & 8 & 27.6 & 9 & 31.0 & 8 & 53.3 \\
\hline AN binge eating/purging type & 2 & 6.9 & 5 & 17.2 & 0 & 0 \\
\hline $\mathrm{BN}$ & 8 & 27.6 & 11 & 37.9 & 1 & 6.7 \\
\hline BED & 3 & 10.3 & 2 & 6.9 & 1 & 6.7 \\
\hline Total & 29 & 100 & 29 & 100 & 15 & 100 \\
\hline
\end{tabular}

Table 3

Distribution of the methods of NSSI into each cluster

\begin{tabular}{|lllllll|}
\hline & \multicolumn{2}{l}{ Cluster $\mathbf{1}$} & \multicolumn{2}{c|}{ Cluster 2 } & \multicolumn{2}{c|}{ Cluster 3 } \\
\cline { 2 - 8 } & $\mathbf{n}$ & $\%$ & $\mathbf{n}$ & $\%$ & $\mathbf{n}$ & $\%$ \\
\hline Method of NSSI & & & & & & \\
\hline Scratching & 15 & 51.7 & 17 & 58.6 & 7 & 46.7 \\
\hline Bruising & 13 & 44.8 & 14 & 48.3 & 9 & 60 \\
\hline Cutting & 15 & 55.2 & 18 & 62.1 & 9 & 60 \\
\hline Burning & 3 & 10.3 & 5 & 17.2 & 4 & 26.7 \\
\hline Biting & 13 & 44.8 & 12 & 41.4 & 5 & 33.3 \\
\hline Other & 10 & 34.5 & 7 & 24.1 & 7 & 46.7 \\
\hline Mean number of methods of NSSI & $\mathrm{M}$ & SD & M & SD & M & SD \\
\cline { 2 - 7 } & 2.41 & 1.32 & 2.52 & 1.55 & 2.73 & 1.44 \\
\hline Note. NSSI = Non-suicidal self-injury. & & & & & & \\
\hline
\end{tabular}

\section{Figures}




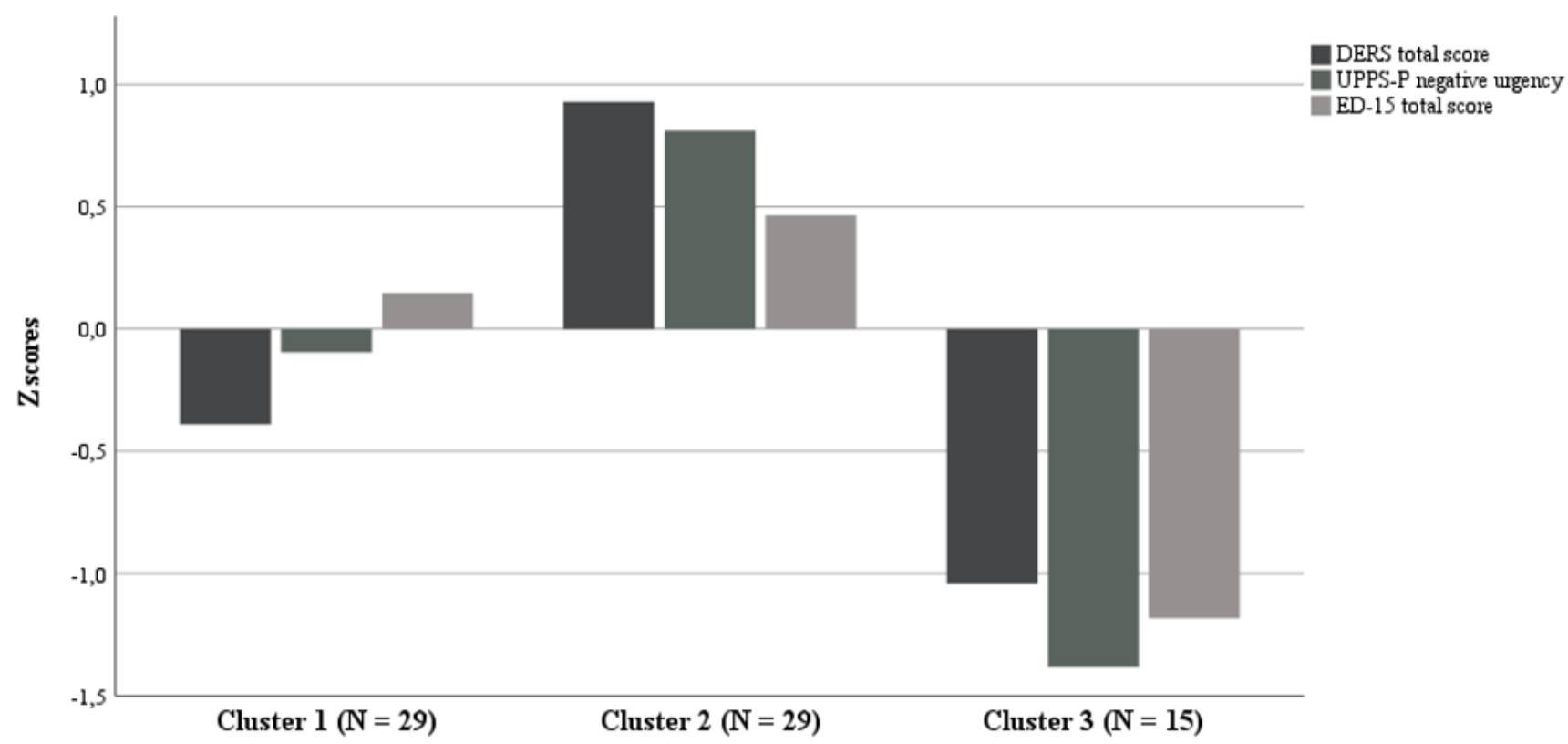

\section{Figure 1}

Clusters characterized by standardized total scores of ED-15, DERS and UPPS-P negative urgency Note. DERS = Difficulties in Emotion Regulation Scale; ED-15 = Eating Disorder-15. 